\title{
Carboplatin/Fluorouracil/Cetuximab Regimen
}

National Cancer Institute

\section{Source}

National Cancer Institute. Carboplatin/Fluorouracil/Cetuximab Regimen. NCI Thesaurus. Code C150686.

A chemoimmunotherapy regimen consisting of carboplatin, fluorouracil (5-FU) and cetuximab that can be used for the treatment of head and neck cancer. 